\title{
Patient Peak Skin Dose and Dose Area Product from Interventional Cardiology Procedures
}

\author{
Antar E. Aly, Ibrahim M. Duhaini, Samia M. Manaa, Sayed M. Tarique, \\ Shehim E. Kuniyil, Huda M. Al Naemi \\ Hamad Medical Corporation, Doha, Qatar \\ Email: anter protect@yahoo.com
}

Received 26 December 2014; accepted 8 January 2015; published 16 January 2015

Copyright (C) 2015 by authors and Scientific Research Publishing Inc.

This work is licensed under the Creative Commons Attribution International License (CC BY). http://creativecommons.org/licenses/by/4.0/

c) (i) Open Access

\begin{abstract}
Information about the peak skin dose and Dose Area product (DAP) from percutaneous transluminal coronary angioplasty (PTCA) and coronary angiography (CA) was collected from three catheter application rooms. The range of maximum photon energy was $50-125 \mathrm{kVp}$ and the fluoroscopy time was 0.6 - 52 seconds. Values of up to $143 \mathrm{~Gy} \cdot \mathrm{cm}^{2}$ for DAP and $0.752 \mathrm{mGy}$ for cumulative dose (CD) were found in CA procedures. Otherwise the DAP and CD for PTCA were found to be $143 \mathrm{~Gy} \cdot \mathrm{cm}^{2}$ and $2.287 \mathrm{mGy}$ respectively in 3rd Quartile. The relation between the fluoroscopy time and the DAP is also considered. Objectives: The objective of this study is to obtain information about patient peak skin doses (PSD), dose area product (DAP), Fluoroscopy Time (FT) and Cumulative Dose (CD) from PTCA and CA which is the most predominant with respect to high skin doses in addition to other procedures. The aim of this study is also to assess the radiation dose received by patients undergoing interventional radiology procedures, by identifying the procedures that deliver the highest doses. This study is also helpful to establish the reference dose level for adult patients undergoing interventional procedure, and to provide recommendations on how to reduce dose on selected procedures that have been identified to deliver patient dose values near the ICRP (International Commission on Radiological Protection) threshold values.
\end{abstract}

\section{Keywords}

Interventional Radiology, Patient Dose, Fluoroscopy Time, Peak Skin Dose

\section{Introduction}

Radiation induced skin effects are deterministic in nature, with a generally accepted threshold dose of 2 Gy [1]

How to cite this paper: Aly, A.E., Duhaini, I.M., Manaa, S.M., Tarique, S.M., Kuniyil, S.E. and Al Naemi, H.M. (2015) Patient Peak Skin Dose and Dose Area Product from Interventional Cardiology Procedures. International Journal of Medical Physics, Clinical Engineering and Radiation Oncology, 4, 7-12. http://dx.doi.org/10.4236/ijmpcero.2015.41002 
[2]. Peak skin dose has been implemented as a function of the highest radiation dose at any point in patient to stand for the likelihood and severity of radiation-induced skin injury to the patient [1] [3]. The European Union requires that all new interventional and paediatric fluoroscopic equipment incorporate DAP measurement capability. This technology is often available (frequently as an added-cost option) on interventional equipment sold in the United States. DAP is measured in units of $\mathrm{Gy} \cdot \mathrm{cm}^{2}$ and expresses the total X-ray flux in the beam [4]. Because dose decreases proportionately to the square of the distance from the focal spot, and the area of the irradiated field increases proportionally in the same way, DAP is independent of source-to-skin distance [5]. For almost half a century prior to the 1990s, it was difficult to see reports of skin injuries even for staff [6]. The increase in use of fluoroscopy for complicated interventions, which require long fluoroscopy time coupled with a continued lack of awareness among many interventionists and a lack of dose monitoring or no understanding of dose parameters, has resulted in continued occurrence of skin injuries.

\section{DAP Meter Calibration}

The calibration factor has to take into account the differences between the dose area product (DAP) displayed by the transmission chamber placed on the collimator and the DAP of the radiation affecting on the patient [6]. The calibration factor is the ratio between the DAP of the radiation which actually impinges on the patient, and the value displayed by the DAP meter. Place the ionization chamber on top of the mattress. Build something to put 4 cm of PMMA sheets on top of the ionization chamber to avoid backscatter. Maintain fluoroscopy until the system accumulates a DAP around $10 \mathrm{~Gy} \cdot \mathrm{cm}^{2}$. Record the accumulated dose with the reference ionization chamber $D_{\text {ref }}$ and the DAP measured by the system.

$D A P_{i}$ : Initial Dose Area Product, from the X-Ray System before irradiation.

$D A P_{f}$ : Final Dose Area Product, from the X-Ray System after irradiation,

$D_{\text {ref: }}$ : Dose reading from the ionization chamber (Barracuda).

Applied the next formula to estimate the calibration factor (f) which is equal 0.81 to 0.88 in this study.

$$
f=\frac{D_{\text {ref }} \cdot \text { Area }}{D A P_{f}-D A P_{i}}
$$

Quality control for fluoroscopy machines is also assessed including $\mathrm{kVp}$, mA beam quality (Half-Value Layer [HVL]) assessment, image quality evaluation and Patient exposures.

\section{Materials and Methods}

Four X-ray fluoroscopic machines from HMC (Hamad Medical Corporation) in the state of Qatar (one Cath-Lab in Hamad General Hospital and three in Heart Hospital) performing Interventional Cardiology (IC) procedures were engaged in this study. All machines are manufactured by Siemens with a flat panel detector in a C-arm configuration. Radiation doses for approximately 1132 patients were collected including patients' age, gender, and fluoroscopy time (FT), and total DAP readings. In order to establish reference dose levels (RDLs), the third quartile of value from survey data distribution was calculated. The median values of the distribution were also assessed in order to estimate the variation in values. The RDLs were also compared with the RDLs provided by the European Research program (DIMOND) and other references. Total number of patient, age and total number of procedures during the period from 2007 to 2012 are illustrated in Figure 1.

\section{Result and Discussion}

Radiation doses for 1132 patients were collected include patients age, sex, fluoroscopy time (FT), total DAP reading. The range of $\mathrm{kVp}$ used in these procedures was $50-125 \mathrm{kVp}$ and the fluoroscopy time 0.18 - $52 \mathrm{mi}-$ nutes. For CA procedures, the Dose Area Product values reached $72.14 \mathrm{~Gy} \cdot \mathrm{cm}^{2}$ and the Cumulative Dose values reached $752 \mathrm{mGy}$. On the other hand, the DAP for and CD for PTCA procedures were found to be $143 \mathrm{~Gy} \cdot \mathrm{cm}^{2}$ and 2287 mGy respectively. Cumulative Dose (CD) was of the order of $2 \mathrm{~Gy}$, the dose limit for radiation injuries. The relation between the fluoroscopy time and the DAP are also considered. It is noticed that the DAP value for CA in Diamond RLs exceeded the HMC DRLs by almost $20 \%$ for 3rd quartile values. DAP and decrease in fluoroscopy time was noticed in HMC for the same procedures as shown in Table 1.

However DAP is a poor indicator of onset of deterministic effects. A much better indicator is skin entrance 


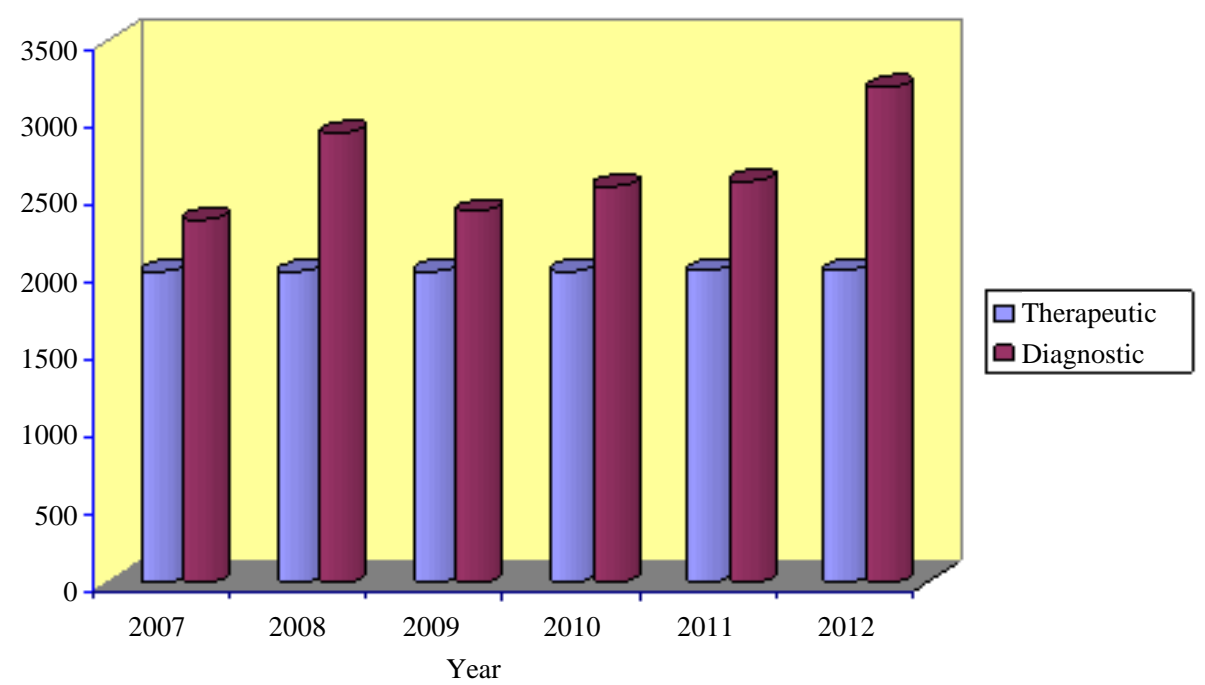

Figure 1. Total number of procedures during the period from 2007 to 2012.

Table 1. Dose parameters for PTCA and CA for HMC and different references levels.

\begin{tabular}{ccccccccc}
\hline \multirow{2}{*}{ Parameter } & \multicolumn{2}{c}{$\begin{array}{c}\text { HMC Qatar } \\
\text { CA }\end{array}$} & \multicolumn{2}{c}{$\begin{array}{c}\text { HMC Qatar } \\
\text { PTCA }\end{array}$} & \multicolumn{2}{c}{ DIMOND 2008 } & \multicolumn{3}{c}{ I.Mavrikov et al. } \\
& Median & 3rd Quartile & Median & 3rd Quartile & 3rd Quartile & 3rd Quartile & 3rd Quartile & 3rd Quartile \\
\hline $\begin{array}{c}\text { DAP Gy·cm } \\
\text { F. Time }\end{array}$ & 53.12 & 72.14 & 91.9 & 143.7 & 57 & 94 & 66.3 & 158 \\
$\begin{array}{c}\text { Min. } \\
\text { CD }\end{array}$ & 2.35 & 4.67 & 4.99 & 8.0 & 6.0 & 16 & 7.7 & 21.4 \\
$\begin{array}{c}\text { mGy } \\
\text { PSD } \\
\text { mGy }\end{array}$ & 379 & 752 & 1215 & 2287 & - & - & 780 & 2009 \\
\hline
\end{tabular}

dose and, specifically PSD, which is the highest dose in any part of the patient's skin during any interventional procedures and is usually measured in Gy or mGy. Modern X-ray machines provide a quantity that correlates with patient skin dose and PSD, the reference point air kirma (RPAK). RPAK is a measure of the radiation level in a specific point relative to the interventional reference point. This point which is along the central axis of the $\mathrm{X}$-ray beam and $15 \mathrm{~cm}$ from the isocenter, is close to the patient's skin surface and is provided by the manufacturer. RPAK was introduced by the International Electrotechnical Commission [7] for standardization purposes and is similar to the reference dose and the cumulative dose used in the past. These three terms can be found in the control units of X-ray machines together with KAP. It does not take into account the scattered radiation and, therefore, is not the actual dose to the patient's skin. For this reason, the latest guidelines of the society of Interventional Radiology (SIR) Safety and Health Committee presented a conversion formula to help operators estimate the PSD from the RPAK shown on the X-ray machine at the end of interventional procedure (8):

$$
\mathrm{PSD}=206+0.513 * \mathrm{RPAK}
$$

However, it should be noted that this is a broad approximation and not an actual measurement; it cannot be used when RPAK values are below 500 mGy [8]. In order to avoid skin damage, such as transient erythema (2000) msv, the DAP value should not be larger than approximately 520 and $280 \mathrm{~Gy}^{\circ} \mathrm{cm}^{2}$ for CA and CA plus PTCA which is similar value obtained by Hassan and Karambaskidou [9]. In this study the Dose area product registered only $4.5 \%$ from the total number of the patients increase than $100 \mathrm{~Gy} \cdot \mathrm{cm}^{2}$ as shown in Figure 2 . So this study is under control for the values of DAP compared Karambaskidou.

The relation between cumulative DAP and PSD was investigated for both diagnostic and therapeutic interventions based on all data. These data are presented graphically in Figure 3. In this study it found that a strong correlation between the Dose Area product and PSD $\left(\mathrm{R}^{2}=0.87\right)$, conversely, as shown in Figure 4 , there is a poor 
correlation between the total fluoroscopy time (FT) and the PSD $\left(\mathrm{R}^{2}=0.39\right)$. Table 2 illustrate the comparing between HMC data for PTCA procedure with different countries results in a work conducted by Tsapaki et al. [10], HMC patients have save dose for the average dose less than $100 \mathrm{~Gy} \cdot \mathrm{cm}^{2}$.

For all patients with coronary angiography $78 \%$ peak skin doses were well below $1 \mathrm{~Gy}$. This indicated that patients undergoing these diagnostic investigations are unlikely to receive doses sufficient to cause deterministic effects. The distribution of peak skin dose (PSD) for CA procedures is shown in Figure 5. The PSD of 1.2\% from the total number of patients were more than $2 \mathrm{~Gy}$. If these patients do perform PTCA at a later time, they may likely for early transient skin injury.

Table 2. Countries with hospitals reporting DAP Data specifically on (PTCA) procedures.

\begin{tabular}{|c|c|c|c|c|c|}
\hline \multirow{2}{*}{ Country } & \multicolumn{4}{|c|}{ No. of Patients with DAP $\left(\mathrm{Gy} \cdot \mathrm{cm}^{2}\right)$} & \multirow{2}{*}{ DAP $<100 \%$ of Patients Exam } \\
\hline & $<100$ & $101-200$ & $201-300$ & $301-400$ & \\
\hline Qatar (HMC) & 740 & 46 & 2 & 0 & 93.9 \\
\hline Algeria & 10 & 8 & 3 & 0 & 45 \\
\hline Kenya & 18 & 5 & 1 & 0 & 75 \\
\hline Tunisia & 14 & 20 & 11 & 0 & 30 \\
\hline Lebanon & 32 & 11 & 3 & 2 & 67 \\
\hline Syria & 33 & 21 & 9 & 4 & 46 \\
\hline Thailand & 9 & 8 & 2 & 0 & 50 \\
\hline United Arab E & 374 & 81 & 8 & 5 & 80 \\
\hline Pakistan & 4 & 12 & 14 & 0 & 12 \\
\hline Bulgaria & 68 & 19 & 4 & 1 & 72 \\
\hline Croatia & 140 & 12 & 1 & 0 & 92 \\
\hline Greece & 25 & 7 & 0 & 0 & 78 \\
\hline Lithuania & 42 & 0 & 0 & 0 & 100 \\
\hline Slovenia & 221 & 59 & 9 & 0 & 76 \\
\hline
\end{tabular}

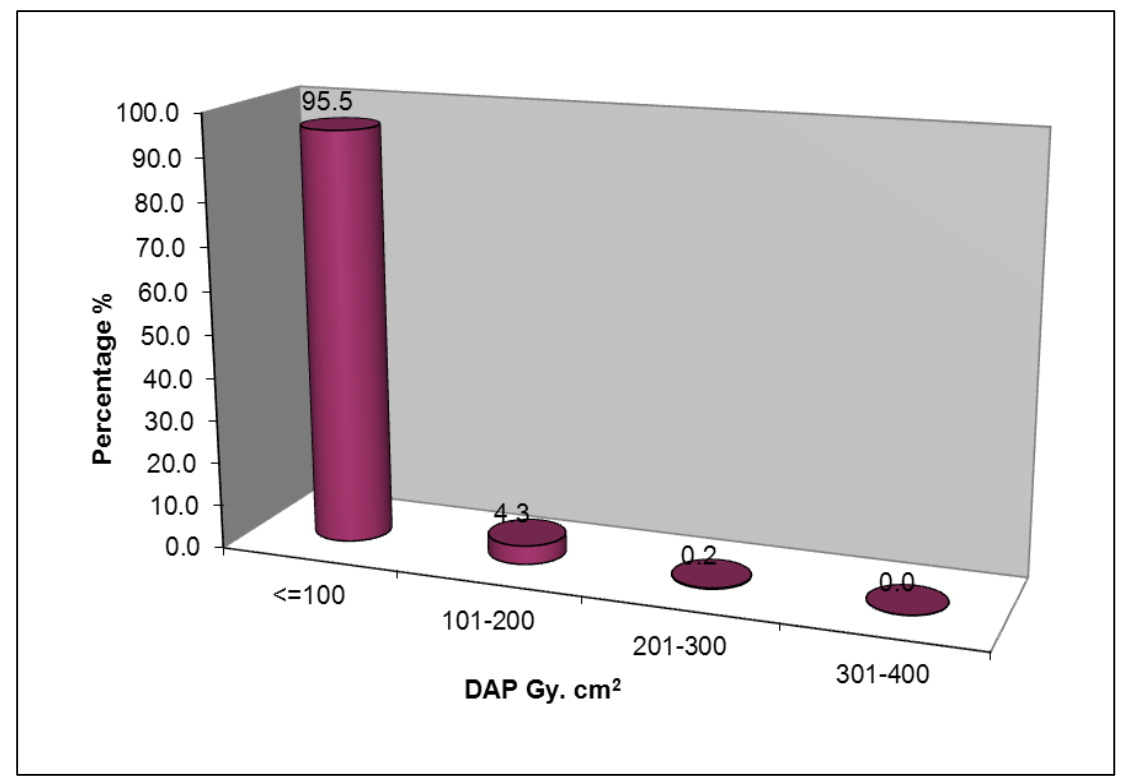

Figure 2. Distribution of the dose area product (DAP) for PTCA procedures. 


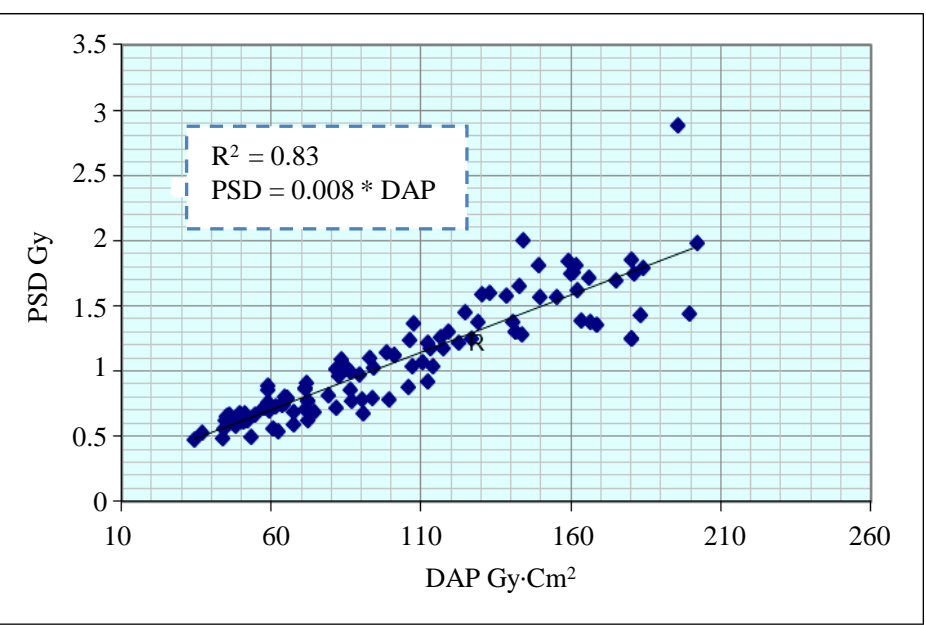

Figure 3. The relation between peak skin dose and dose area product for high skin doses.

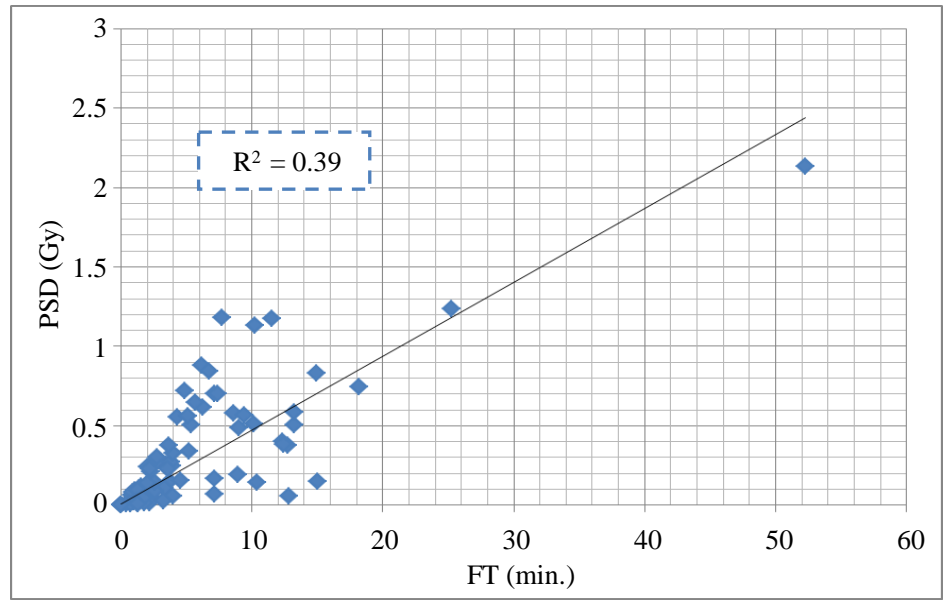

Figure 4. Correlation between fluoroscopy time and peak skin dose.

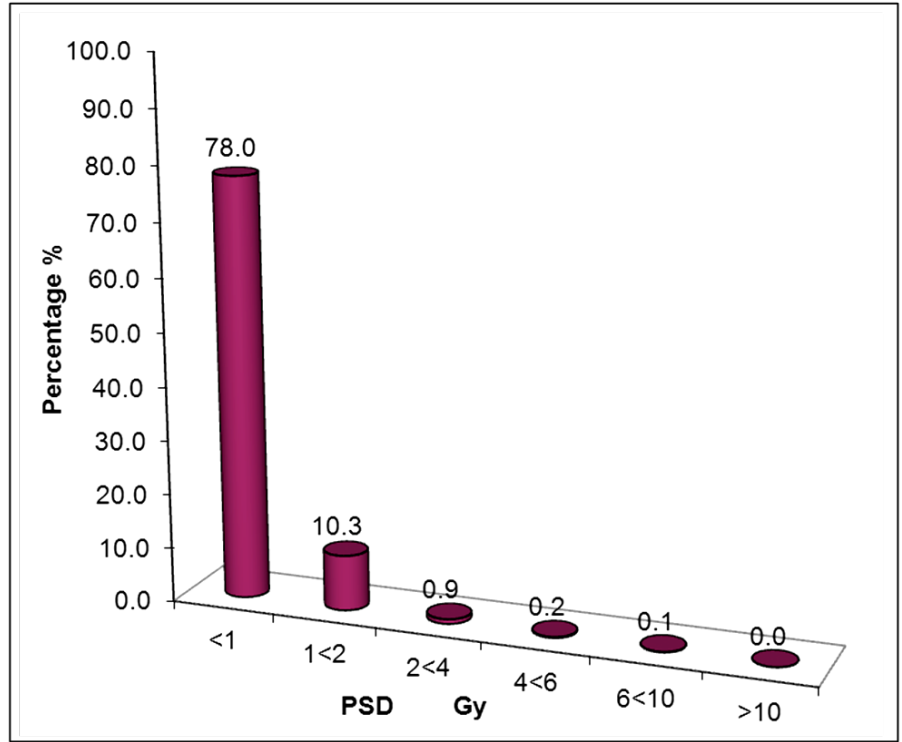

Figure 5. The distribution of peak skin dose (PSD) for CA procedures. 


\section{Conclusion}

In this study, a strong correlation was found between the (DAP) and (PSD). Conversely, there is a poor correlation between the Total Fluoroscopy Time (FT) and the PSD. So, in this study the total DAP can be used as an indicator for PSD. On the other hand, Fluoroscopy Time was found to be a much less reliable indicator of the Peak Skin Dose. The proposed reference levels based on DAP readings are thus about $100 \mathrm{~Gy} \cdot \mathrm{cm}^{2}$, corresponding to PSD of about less than 2 Gy.

\section{References}

[1] Wagner, L.K., Eifel, P.J. and Geise, R.A. (1994) Potential Biological Effects Following High X-Ray Dose Interventional Procedures. Journal of Vascular and Interventional Radiology, 5, 71-84. http://dx.doi.org/10.1016/S1051-0443(94)71456-1

[2] Koenig, T.R., Wolff, D., Mettler, F.A. and Wagner, L.K. (2001) Skin Injuries from Fluoroscopically Guided Procedures: Part 1, Characteristics of Radiation Injury. American Journal of Roentgenology, 177, 3-11. http://dx.doi.org/10.2214/ajr.177.1.1770003

[3] Shope, T.B. (1996) Radiation-Induced Skin Injuries from Fluoroscopy. RadioGraphics, 16, 1195-1199. http://dx.doi.org/10.1148/radiographics.16.5.8888398

[4] Balter, S. (2001) Interventional Fluoroscopy: Physics, Technology, Safety. Wiley-Liss, New York.

[5] Faulkner, K., Broadhead, D.A. and Harrison, R.M. (1999) Patient Dosimetry Measurement Methods. Applied Radiation and Isotopes, 50, 113-123. http://dx.doi.org/10.1016/S0969-8043(98)00031-1

[6] Fernandez, J.M., Simon, R., Prieto, C., Martinez, D. and Vano, E. (2006) Medical Physics Service. San Carlos University Hospital Version 12, April 2006.

[7] International Electrotechnical Commission (2000) IEC 2000: Particular Requirements for the Safety of X-Ray Equipments for Interventional Procedure. IEC 60601-60602-60603, Geneva.

[8] Stecker, M.S., Balter, S. and Towbin, R.B. (2009) Guideline for Patient Radiation Dose Management. Journal of Vascular and Interventional Radiology, 20, 263-273.

[9] Hansson, B. and Karambatsakidou, A. (2000) Relationships between Entrance Skin Dose, Effective Dose and Dose Area Product for Patients in Diagnostic and Interventional Cardiac Procedures. Radiation Protection Dosimetry, 90, 141-144. http://dx.doi.org/10.1093/oxfordjournals.rpd.a033104

[10] Tsapaki, V., Nada, A., Adnan, B., Abdelkader, B., et al. (2009) Radiation Exposure to Patients during Interventional Procedures in 20 Countries: Initial IAEA Project Results. American Journal of Roentgenology, 193, 559-569. http://dx.doi.org/10.2214/AJR.08.2115 
Scientific Research Publishing (SCIRP) is one of the largest Open Access journal publishers. It is currently publishing more than 200 open access, online, peer-reviewed journals covering a wide range of academic disciplines. SCIRP serves the worldwide academic communities and contributes to the progress and application of science with its publication.

Other selected journals from SCIRP are listed as below. Submit your manuscript to us via either submit@scirp.org or Online Submission Portal.
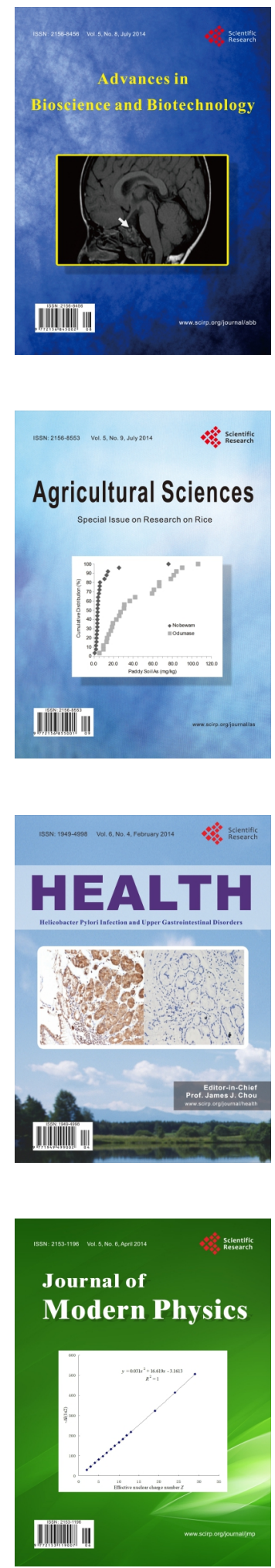
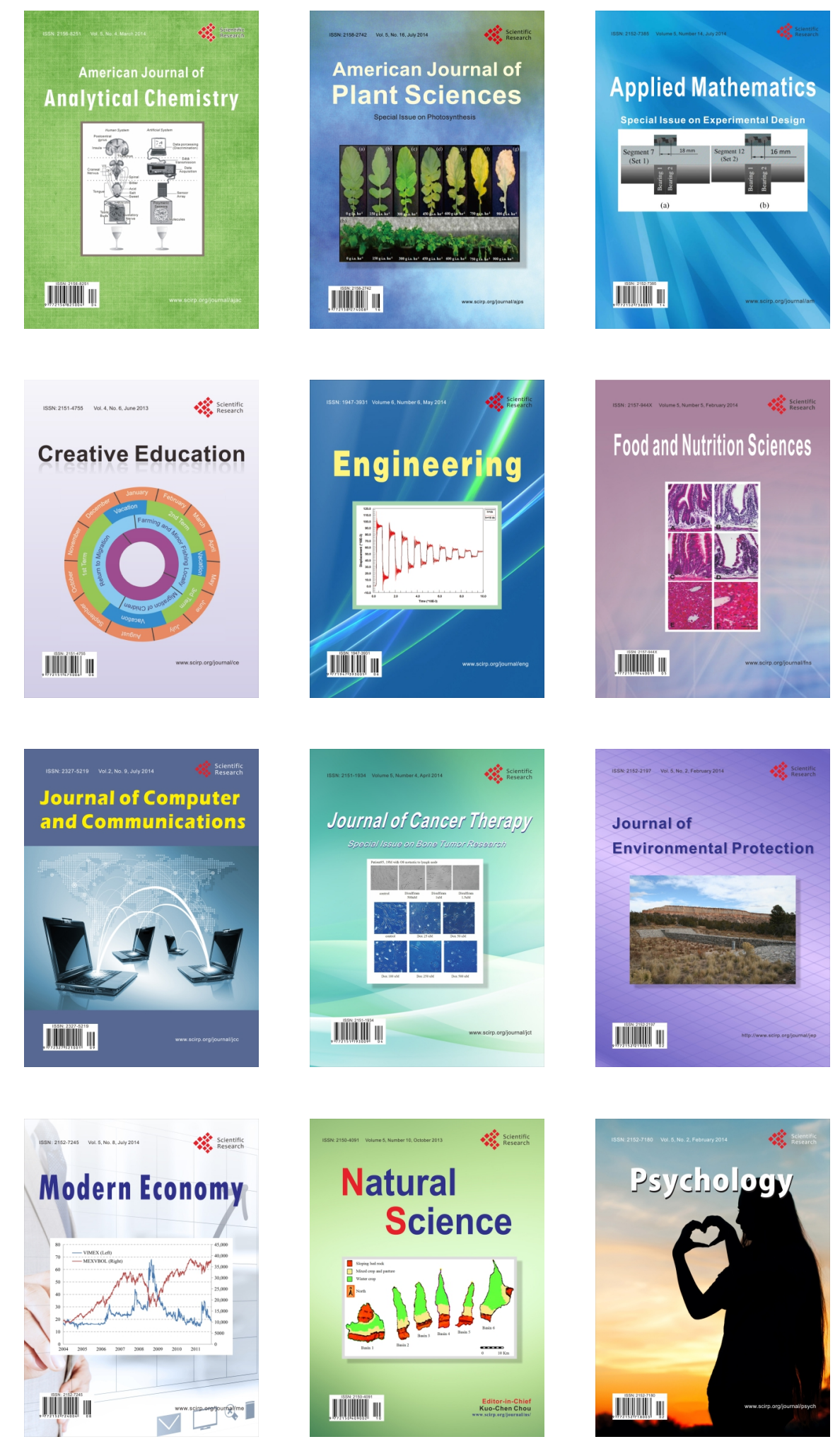